\title{
A DELAÇÃO DA JBS, O BNDES, AS SALSICHAS E A PROMISCUIDADE NAS RELAÇÕES FINANCEIRAS
}

Coluna publicada em 30.5.2017: <https://www.conjur.com.br/2017-mai-30/ contas-vista-delacao-jbs-bndes-promiscuidade-relacoes-financeiras $>$

Os escândalos que não cessam em nosso País novamente fazem todos voltar a atenção para as pouco conhecidas e compreendidas relações entre o setor público e privado por meio dos bancos de fomento, como é o caso do BNDES, já objeto de referência em coluna anterior. ${ }^{1}$ E que está novamente no centro das atençôes, com a recente alteração na presidência do órgão.

$\mathrm{Na}$ delação dos controladores da empresa JBS, mais conhecida pela sua atuação no ramo frigorífico pela sua marca Friboi, ficaram evidentes as relações ao que tudo indica pouco republicanas entre o setor público e o privado envolvendo o BNDES, responsável entre outras atribuições por manter linhas de financiamento voltadas a cumprir sua missão de "Promover o desenvolvimento sustentável e competitivo da economia brasileira, com geração de emprego e redução das desigualdades sociais e regionais", atento aos valores da ética, compromisso com o desenvolvimento, espírito público e excelência. ${ }^{2}$

A atividade financeira do setor público, que tem nas leis orçamentárias seu principal instrumento normativo, deve ser transparente, daí porque os orçamentos têm por princípios, dentre outros, o da universalidade e da unidade, fazendo dele um documento que permita ao administrador público e à sociedade conhecer a origem e o destino de todos os recursos públicos pela análise de uma única peça - o que não é uma tarefa simples.

1 BNDES tem o dever de colaborar com a transparência dos gastos públicos, nesta edição, p. 411416.

2 <http://www.bndes.gov.br/wps/portal/site/home/quem-somos/governanca-controle/planejamento-corporativo/missao $\% 2 \mathrm{C}$-visao-e-valores> 
Apesar dos esforços no sentido de aperfeiçoar a contabilidade pública, há ainda lacunas importantes, com vultosas operaçôes financeiras que, como já escrito na coluna há pouco citada, "tendem a ficar à margem da lei orçamentária, compondo o que já se conhece como off-budget expenditures, tais como os gastos tributários e os benefícios creditícios, cuja não contabilização adequada acarreta grande prejuízo à transparência fiscal".

Mencionados no artigo $165, \$ 6^{\circ}$, da Constituição, os benefícios financeiros e creditícios devem integrar a lei orçamentária anual para efeitos de conferir transparência a essas medidas financeiras que, para muitos efeitos, configuram subsídios aos setores econômicos que deles se beneficiam. Assemelham-se, em alguns aspectos, a outras modalidades de renúncia, pelo Estado, de parcela dos recursos que poderia arrecadar. E, muitas vezes, são "gastos invisíveis", cuja dimensão deve ser apurada por metodologias específicas, no mais das vezes estimativas. Daí a justificada preocupação constitucional com sua previsão orçamentária, referindo-se expressamente à necessidade de sua presença nas leis de planejamento orçamentário da administração pública.

Os benefícios financeiros e creditícios, como muito bem exposto por José Maria Arruda de Andrade em texto relativamente recente publicado aqui mesmo no ConJur, são ainda "ilustres desconhecidos", 3 e a expressividade de seu montante não permite ignorá-los, atingindo o montante de $\mathrm{R}$ \$ 107,7 bilhões em 2015, como menciona no referido texto, o que se manteve em $2016 .{ }^{4}$

Nos benefícios financeiros e creditícios há a concessão de subsídios por meio de programas voltados à expansão do crédito. Tratando-se de benefícios financeiros, o concedente realiza desembolsos pela via de equalizações de juros e preços, assim como assume dívidas decorrentes do saldo das obrigações de sua responsabilidade. No caso dos benefícios creditícios, opera-se por meio de programas oficiais de crédito, cuja execução se torna viável por meio de fundos e programas criados para este fim, com taxas de juros inferiores ao custo de captação, de forma a incentivar setores produtivos e promover o desenvolvimento regional e setorial. ${ }^{5}$ Em qualquer caso, esta diferença nas taxas de juros ou preços que o governo paga e oferece gera consideráveis desembolsos em apoio a setores produtivos. Fala-se,

3 Benefícios financeiros e creditícios: esses ilustres desconhecidos, em 14 de agosto de 2016.

4 Governo gasta R\$ 107 bi só com subsídios, Folha de S.Paulo, 29 de maio de 2017, p. A17.

5 <http://portal.tcu.gov.br/comunidades/macroavaliacao-governamental/areas-de-atuacao/renuncia-de-receita/> 
portanto, em subsídios, nem todos explícitos no orçamento. Os benefícios creditícios são, particularmente, marcados pela opacidade, pois não aparecem no orçamento. ${ }^{6}$ Como ressaltado com precisão por Emerson Gomes, ao tratar com propriedade do tema, "são também chamados de benefícios ou subsídios implícitos, em função de não constarem do Orçamento Geral da União. Os gastos são decorrência do fato de os recursos do Tesouro alocados a estes programas terem uma taxa de retorno inferior ao seu custo de captação"?

Os Tribunais de Contas têm competência para fiscalizar as renúncias de receitas, conforme dispõe o artigo 70 da Constituição Federal. No caso federal, esta atribuição vem, ainda, regulamentada pelo artigo $1^{\circ}, \$ 1^{\circ}$, da Lei Orgânica do Tribunal de Contas da União. ${ }^{8}$ A Secretaria de Macroavaliação Governamental (Semag) do TCU conduziu relevante processo de auditoria apresentado em 2012 voltado a identificar os tipos e os montantes dos benefícios explícitos e implícitos, assim como sua distribuição regional. Ali se determinou que a Secretaria de Política Econômica do Ministério da Fazenda, em conjunto com a STN, em relação às operações de crédito realizadas entre a União e o BNDES a partir de 2008, realizasse "projeções que permitam conhecer o montante total de benefícios financeiros e creditícios concedidos pela União, contemplando os subsídios previstos para todo o período de duração dos empréstimos e apresentando recorte específico para os quatro anos seguintes, informando os resultados e a metodologia ao TCU até 31 de março de cada exercício, com fundamento no art. 71 da Constituição Federal, c/c o art. 36 da Lei 8.443/1992"?

O Grupo JBS, pelo que agora se soube, aproveitou-se indevidamente desses benefícios, causando grandes prejuízos financeiros aos cofres públicos, sem contar o prejuízo moral decorrente dos métodos utilizados para consegui-los.

A complexidade das operações realizadas, com consequente dificuldade de análise, avaliação, acompanhamento e fiscalização, fica evidenciada, por exemplo,

6 Vide DINIZ, Érica; AFONSO, José Roberto. Benefícios fiscais concedidos (e mensurados) pelo Governo Federal (texto de discussão), FGV/IBRE, janeiro de 2014.

7 O direito dos gastos públicos no Brasil. São Paulo: Almedina, 2015. p. 161.

8 De acordo com o referido dispositivo da Lei 8.443/1992, que, no "julgamento de contas e na fiscalização que lhe compete, o Tribunal decidirá sobre a legalidade, a legitimidade e a economicidade dos atos de gestão e das despesas deles decorrentes, bem como sobre a aplicação de subvençôes e a renúncia de receitas".

9 BRASIL. Tribunal de Contas da União. Acórdão 1966/2013, rel. Min. Aroldo Cedraz, p. 47. 
na aquisição que o Grupo JBS fez da empresa norte-americana Swift, com apoio financeiro do BNDES, que foi objeto de investigação preliminar pelo Tribunal de Contas da União.

No Acórdão TCU 800/2017, relata-se que o BNDES, por meio de sua subsidiária BNDESPar, prestou apoio financeiro à operação, no montante de $\mathrm{R}$ \$ 1,1 bilhão (US\$ 573 milhões à época), tendo sido apuradas várias irregularidades, como falta de clareza na aplicação dos recursos solicitados, ausência de análise criteriosa da operação e verificação dos benefícios econômicos e sociais dela decorrentes, entre outras.

O relator, Min. Augusto Sherman Cavalcanti, chama a atenção para os subsídios implícitos e o impacto que promovem na dívida pública, sendo claro ao destacar que "o conjunto de indícios é no sentido de que o BNDESPar utilizou-se de recursos caros para o país e para os contribuintes para viabilizar a aquisição de uma empresa norte-americana pela JBS, sem análise aprofundada de viabilidade econômica do investimento, concedendo recursos em montante superior ao necessário, sem acompanhamento posterior adequado da operação, por meio da aquisição de ações da referida empresa com ágio que não se justifica frente às informações carreadas aos autos, e, especialmente, sem qualquer análise dos benefícios que tal operação poderia trazer para o país e para seus cidadãos" ${ }^{10}$

Os valores de recursos públicos envolvidos têm uma dimensão espantosa, e a sabedoria popular já ensina que quando a tentação é grande a carne é fraca. É difícil até imaginar quantos bens e serviços poderiam ser levados aos mais necessitados com tanto dinheiro que está sendo desperdiçado.

Se não houver melhor regulamentação e fiscalização dessas operações, continuaremos a ver empresários enriquecendo às custas do dinheiro que é de todos nós, e com ele desfrutar das delícias de Nova York (nas quais se espera sejam incluídos seus famosos hot-dogs - com salsichas Friboi, claro!) graças a uma delação "especialmente premiada".

Nessa delação, muito se aprendeu sobre o funcionamento das relações pouco republicanas entre o setor público e o privado, levando-nos a conhecer como funciona boa parte do sistema de financiamentos privilegiados concedidos pelo setor público, e da forma pela qual se fazem leis que concedem esses generosos benefícios tributários, financeiros e creditícios.

10 TCU, Acórdão 800/2017, rel. Augusto Sherman Cavalcanti, sessão de 26 de abril de 2017, p. 60. Grifos do original. 
Uma pena que nossos diligentes procuradores perderam a oportunidade de ter questionado os delatores, que são especialistas no assunto e o conhecem como ninguém, sobre aquele que é um dos grandes mistérios da humanidade e talvez um dos mais bem guardados segredos de todos os tempos: como são feitas as salsichas?

Já disse há séculos Otto Von Bismarck que, "quanto menos as pessoas souberem como são feitas as salsichas e as leis, mais tranquilas dormirão". ${ }^{11}$

Infelizmente ainda temos muitos motivos para não podermos dormir tranquilos...

11 No original, "Je weniger die Leute davon wissen, wie Würste und Gesetze gemacht werden, desto besser schlafen sie". Muitas vezes encontra-se a frase traduzida por "leis são como salsichas: é melhor não saber como são feitas". 
